\title{
Transmetalation Reactions Triggered by Electron Transfer between Organocopper Complexes
}

\author{
Olmo Lozano-Lavilla, Pablo Gómez-Orellana, Agustí Lledós,* and Juan A. Casares* \\ Cite This: Inorg. Chem. 2021, 60, 11633-11639 \\ Read Online
}

ABSTRACT: $\left[\mathrm{Cu}\right.$ (bipy) $\left.\left(\mathrm{C}_{6} \mathrm{~F}_{5}\right)\right]$ reacts with most aryl iodides to form heterobiphenyls by cross-coupling, but when $\mathrm{Rf}-\mathrm{I}$ is used ( $\mathrm{Rf}$ = 3,5-dicholoro-2,4,6-trifluorophenyl), homocoupling products are also formed. Kinetic studies suggest that, for the homocoupling reaction, a mechanism based on transmetalation from $[\mathrm{Cu}($ bipy)$\left.\left(\mathrm{C}_{6} \mathrm{~F}_{5}\right)\right]$ to $\mathrm{Cu}(\mathrm{III})$ intermediates formed in the oxidative addition step is at work. Density functional theory calculations show that the interaction between these $\mathrm{Cu}(\mathrm{III})$ species and the starting $\mathrm{Cu}(\mathrm{I})$ complex involves a $\mathrm{Cu}(\mathrm{I})-\mathrm{Cu}(\mathrm{III})$ electron transfer concerted with the formation of an iodine bridge between the metals and that a fast transmetalation takes place in a dimer in a triplet state between two $\mathrm{Cu}(\mathrm{II})$ units.

\section{INTRODUCTION}

Copper occupies a prominent place among the metals used in organic synthesis, and its compounds are extremely versatile and efficient homogeneous catalysts. The Ullmann reaction for the homocoupling of arenes using metallic copper as the catalyst was reported more than a century ago, and during this time milder conditions have been developed by using copper complexes instead of the bulk metal. ${ }^{1,2}$ Simultaneously, methodologies for cross-coupling based on copper have been developed and complement palladium and nickel catalysts. ${ }^{3-6}$

Quite surprisingly, it is difficult to correlate mechanistically both reactions, leading to homocoupling and cross-coupling. By analogy with palladium, the most accepted mechanistic proposal for copper-catalyzed cross-coupling reactions includes the oxidative addition of $\mathrm{R}-\mathrm{X}$ to a $\mathrm{Cu}(\mathrm{I})$, forming a $\mathrm{Cu}(\mathrm{III})$ intermediate in which reductive elimination takes place (Scheme 1). However, mechanisms involving radical oxidation to produce $\mathrm{Cu}(\mathrm{II})$ intermediates seem to operate in a significant number of reactions, and $\mathrm{Cu}$ (II) intermediates have been invoked in several mechanistic proposals for the Ullmann reaction. ${ }^{2,7,8}$

The two-electron oxidative addition reaction has been addressed in computational and experimental studies. ${ }^{2,9-19}$ It entails an oxidation state change between $\mathrm{Cu}(\mathrm{I})$ (the resting state of the catalyst) and $\mathrm{Cu}(\mathrm{III})$. This is usually the slowest step on the cycle, and unlike what happens in palladiumcatalyzed reactions, the oxidized state, $\mathrm{Cu}(\mathrm{III})$, is often considered to be unstable and therefore a very reactive intermediate. ${ }^{20}$ Hence, the reaction between the $\mathrm{Cu}(\mathrm{I})$ species, very abundant in the reaction medium, and the very reactive $\mathrm{Cu}(\mathrm{III})$ intermediates cannot be disregarded in these systems.

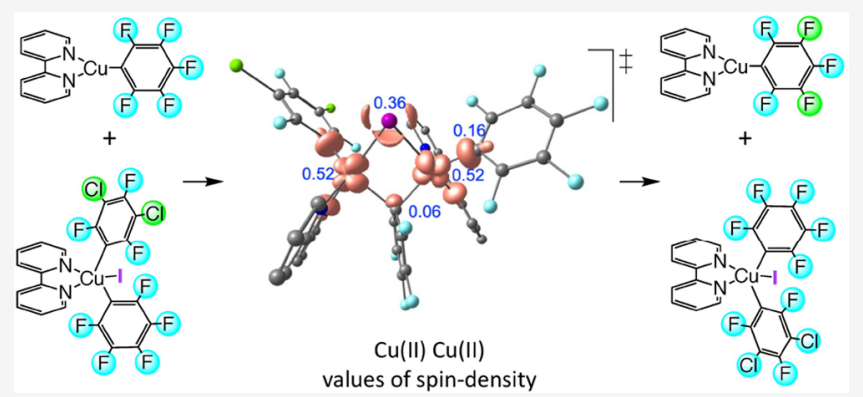

Scheme 1. Accepted Catalytic Cycle for Copper-Catalyzed Cross-Coupling Reactions and the Hypothetical Interaction between $\mathrm{Cu}(\mathrm{III})$ and $\mathrm{Cu}(\mathrm{I})$ Species

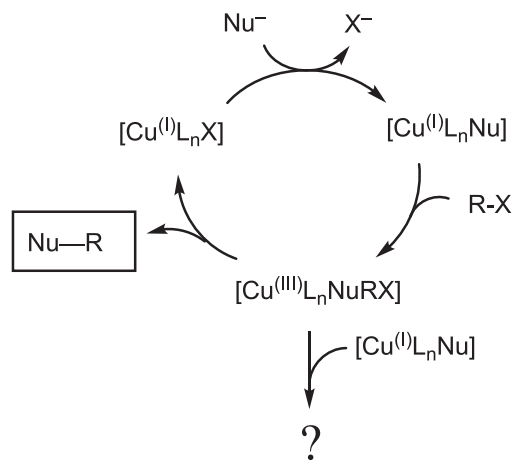

Surprisingly, the interaction between $\mathrm{Cu}(\mathrm{III})$ and $\mathrm{Cu}(\mathrm{I})$ species remains almost unexplored, although the reversal process involving the disproportionation of $\mathrm{Cu}(\mathrm{II})$ organometallics has been proposed as a critical step in several catalytic systems. $^{21,22}$ Also, even though transmetalation between copper species is implicitly assumed in several coupling processes and connects the Ullmann homocoupling reaction with the cross-coupling reaction, transmetalation between

Received: May 27, 2021

Published: July 14, 2021 
$\mathrm{Cu}(\mathrm{I})$ complexes and other copper species has not been explicitly considered in experimental- or computational-based mechanistic proposals. This is striking considering the known ability of $\mathrm{Cu}(\mathrm{I})$ organometallics to transmetalate to other metals, particularly $\mathrm{d}^{8}$ complexes such as $\mathrm{Pd}(\mathrm{II})$ derivatives. $^{23,24}$ This lack of fundamental chemical information prompted us to address the study of these reactions.

\section{RESULTS AND DISCUSSION}

Kinetic Studies. We have pursued to induce the interaction between $\mathrm{Cu}(\mathrm{I})$ and $\mathrm{Cu}(\mathrm{III})$ complexes in transmetalation reactions between $[\mathrm{Cu}($ bipy $)(\mathrm{Pf})]\left(\mathbf{1} ; \mathrm{Pf}=\mathrm{C}_{6} \mathrm{~F}_{5}\right)$ and the putative $\mathrm{Cu}(\mathrm{III})$ intermediates formed after the oxidative addition of aryl iodides to 1 . If the reductive elimination takes place very fast, the cross-coupling product is obtained; otherwise, the $\mathrm{Cu}$ (III) intermediate could be intercepted by reacting with $\mathrm{Cu}(\mathrm{I})$ species (Scheme 2 ).

Scheme 2. Expected Pathways for $\mathrm{Cu}$ (III) Intermediates Formed by Oxidative Addition

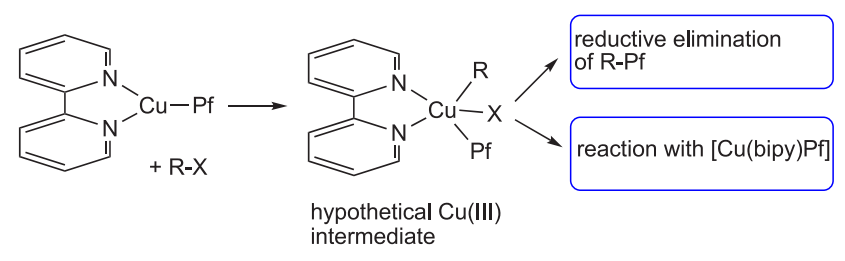

The reactions of $\mathbf{1}$ with nonfluorinated aryl iodides $\mathrm{R}-\mathrm{I}$ follow only the first path, giving the cross-coupling products $\mathrm{R}-\mathrm{Pf}$ without any detectable intermediate and without homocoupling products other than those formed by the basal decomposition of $\mathbf{1}$. The kinetics show a first-order dependence on the copper complex. To explore the influence of the electronic properties of the aryl halides in this reaction, competitive experiments with different para-substituted aryl iodides along with iodobenzene were carried out. For the reaction with $\mathrm{Ph}-\mathrm{I}$ at $50{ }^{\circ} \mathrm{C}, k_{\mathrm{obs}}=2.14 \times 10^{-4} \mathrm{~s}^{-1} \mathrm{M}^{-1}$ and $\Delta G^{\ddagger}{ }_{318.16}=24 \mathrm{kcal} \mathrm{mol}^{-1} .^{25}$ The larger relative rates were obtained for the aryl iodides bearing the most electronwithdrawing substituents, and the Hammett plots of the relative reaction rates displayed a very good correlation with the ${\sigma_{\mathrm{p}}}^{-}$values of the para substituents (Figure 1). The density functional theory (DFT)-computed barriers reproduce this

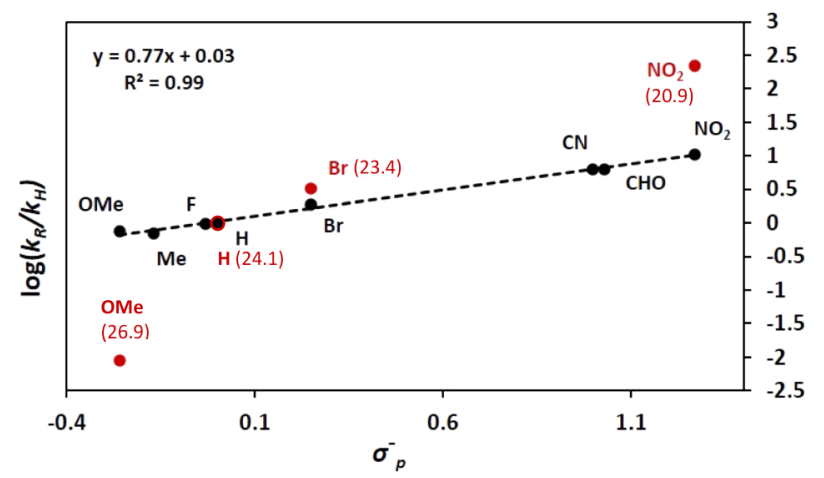

Figure 1. Hammett plot for the reaction rates of the pentafluorophenylation reaction of aryl iodides with the para substituents indicated in the figure. The numbers in red are the computed Gibbs energy barriers in THF, in $\mathrm{kcal} \mathrm{mol}^{-1}$. tendency (red numbers in Figure 1). These results suggest that the reaction behaves as a nucleophilic attack of the copper complex to the ipso-carbon of the aryl iodide, in accordance with previous studies in other $\mathrm{Cu}(\mathrm{I})$ systems. ${ }^{12,26}$ The trend of computed atomic charges at the ipso-carbon agrees with this view (see the Supporting Information, SI).

As reported for analogous systems, 1 suffers a self-ionization equilibrium in solution to give the cation $\left[\mathrm{Cu}(\text { bipy })_{2}\right]^{+}$and the cuprate $\left[\mathrm{Cu}(\mathrm{Pf})_{2}\right]^{-}($eq 1$) .^{12,27,28}$

$$
2[\mathrm{Cu}(\text { bipy })(\mathrm{Pf})] \rightleftharpoons\left[\mathrm{Cu}(\text { bipy })_{2}\right]^{+}+\left[\mathrm{Cu}(\mathrm{Pf})_{2}\right]^{-}
$$

From a van't Hoff plot, the values $\Delta H=-2.7 \pm 0.3 \mathrm{kcal} \mathrm{mol}^{-1}$ and $\Delta S=23 \pm 2 \mathrm{cal} \mathrm{mol}^{-1} \mathrm{~K}^{-1}$ were obtained for this reaction. Using these parameters, $K_{\mathrm{eq}}$ at $25^{\circ} \mathrm{C}$ takes a value of $9 \times 10^{-4}$, meaning that about $97 \%$ of the copper in the system is in the form of the neutral complex 1 . The participation of cuprates in the oxidative addition reaction has been previously discussed, both computationally and experimentally, and in a very general way, it has been found that they react at a much lower rate than the parent neutral tricoordinated complexes. ${ }^{12,29}$ To verify this fact in our system, the tetrabutylammonium salt of the organocuprate $\left(\mathrm{NBu}_{4}\right)\left[\mathrm{CuPf}_{2}\right]$ was synthesized (see the synthesis and X-ray structure in the SI), and the reaction of pentafluorophenylation of iodobenzene was attempted in the same conditions as those for compound 1. Only traces of the heterocoupling product were obtained from this experiment. The same result was obtained by using $\left[\mathrm{Cu}(\text { bipy })_{2}\right]^{+}$or $\left[\mathrm{Cu}(\right.$ bipy) $\mathrm{I}]$ as the copper reagent. ${ }^{14}$

Thus, in principle, the cross-coupling can be pictured as an oxidative addition initiated by a nucleophilic attack of complex 1 on the $\mathrm{C}-\mathrm{I}$ bond to give an intermediate of the type $[\mathrm{Cu}($ bipy $) \mathrm{I}(\mathrm{Pf})(\mathrm{Ar})]$, followed by fast reductive elimination. ${ }^{30}$

In an attempt to stabilize the $\mathrm{Cu}$ (III) species after the nucleophilic attack step, we tested the oxidative addition of 1iodo-3,5-dichloro-2,4,6-trifluorobenzene ( $R f-I)$. The reaction would lead to a $\mathrm{Cu}$ (III) intermediate with two different fluoroaryl substituents that would benefit from the large stabilization of the $\mathrm{C}-\mathrm{M}$ bonds that fluoroaryls provide. ${ }^{31}$ The presumed intermediate was not stable enough to be spectroscopically observed. Instead, in addition to the expected cross-coupling product $\mathrm{Rf}-\mathrm{Pf}$, the homocoupling biaryls $\mathrm{Pf}-\mathrm{Pf}$ and $\mathrm{Rf}-\mathrm{Rf}$ were formed along with $[\mathrm{Cu}($ bipy $)(\mathrm{Rf})]$ and $\mathrm{Pf}-\mathrm{I}$ (Scheme 3).

Two pathways can be envisioned to explain the formation of homocoupling products: a set of double oxidative additionfast reductive elimination reactions (model I in Scheme 4) or a pathway involving $\mathrm{Cu}(\mathrm{III})$ intermediates that react with $\mathbf{1}$ to

\section{Scheme 3. Products Obtained from the Reaction of} Complex 1 with Aryl Iodides ${ }^{a}$

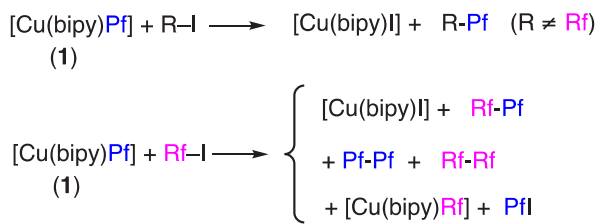

$\mathrm{Rf}=$ 3,5-dicholoro 2,4,6-trifluorophenyl $\mathrm{Pf}=$ pentafluorophenyl

${ }^{a}$ See the SI for reaction conditions and yields. 
form species containing two Pf groups (model II in Scheme 4)..$^{32}$

\section{Scheme 4. Simplified Kinetic Models ${ }^{a}$}

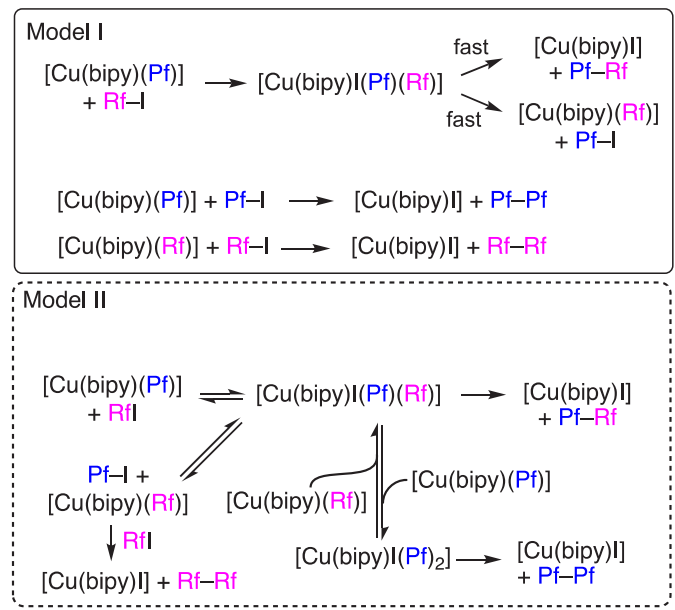

${ }^{a}$ See the SI for a more detailed description. In model I, the homocoupling product $\mathrm{Pf}-\mathrm{Pf}$ is formed after accumulation in the medium of $\mathrm{Pf}-\mathrm{I}$, which can then react with $\mathrm{Cu}(\mathrm{I})$ complexes.

Because $[\mathrm{Cu}($ bipy $)(\mathrm{Rf})]$ is also a reaction product, Pf-Pf and $\mathrm{Rf}-\mathrm{Rf}$ should be formed at the same pace. ${ }^{33}$ Figure 2 shows the formation of products starting from an equimolar mixture of $\mathbf{1}$ and Rf-I and the best nonlinear fittings obtained using models I and II (see the SI for further details) showing the different rates of formation of these two products. Also, the selectivity of the reaction agrees with the involvement of a second copper unit: In model I, the overall selectivity homocoupling/heterocoupling depends competitively on the rates of the reductive elimination of $\mathrm{C}-\mathrm{C}$ and $\mathrm{C}-\mathrm{I}$. On the contrary, in model II, the selectivity depends on the relative kinetic rates of the reductive elimination and transmetalation from the intermediate $[\mathrm{Cu}($ bipy $) \mathrm{I}(\mathrm{Pf})(\mathrm{Rf})]$ (I1) and then on the concentration of $\mathbf{1}$. Figure 3 represents the evolution of the

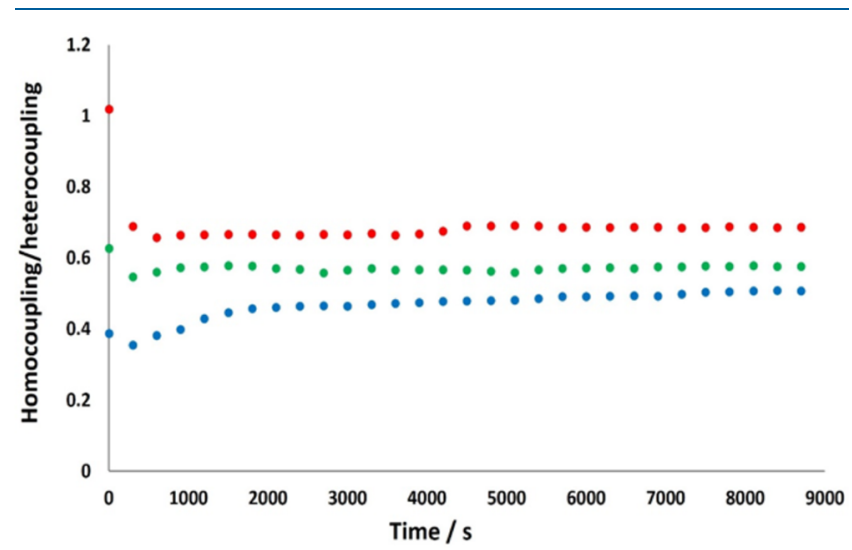

Figure 3. Homocoupling/heterocoupling ratio during the course of the reaction of 1 with $\mathrm{Rf}-\mathrm{I}\left(7.1 \times 10^{-2} \mathrm{M}\right)$ in THF at $25^{\circ} \mathrm{C}$ in reactions with different initial concentration of 1 . The homocoupling accounts for the sum of Pf-Pf plus Rf-Rf: (red dots) $[1]_{0}=1.07 \times$ $10^{-1} \mathrm{M}$; (green dots) $[1]_{0}=7.1 \times 10^{-2} \mathrm{M}$; (blue dots) $[1]_{0}=2.4 \times$ $10^{-2} \mathrm{M}$.

homo/heterocoupling ratio in reactions with different initial concentrations of $\mathbf{1}$. Consistent with model II, the amount of homocoupling products increases with $[\mathbf{1}]_{0}$.

DFT Calculations. Thus, from these results, it seems clear that some kind of transmetalation reaction is involved in the
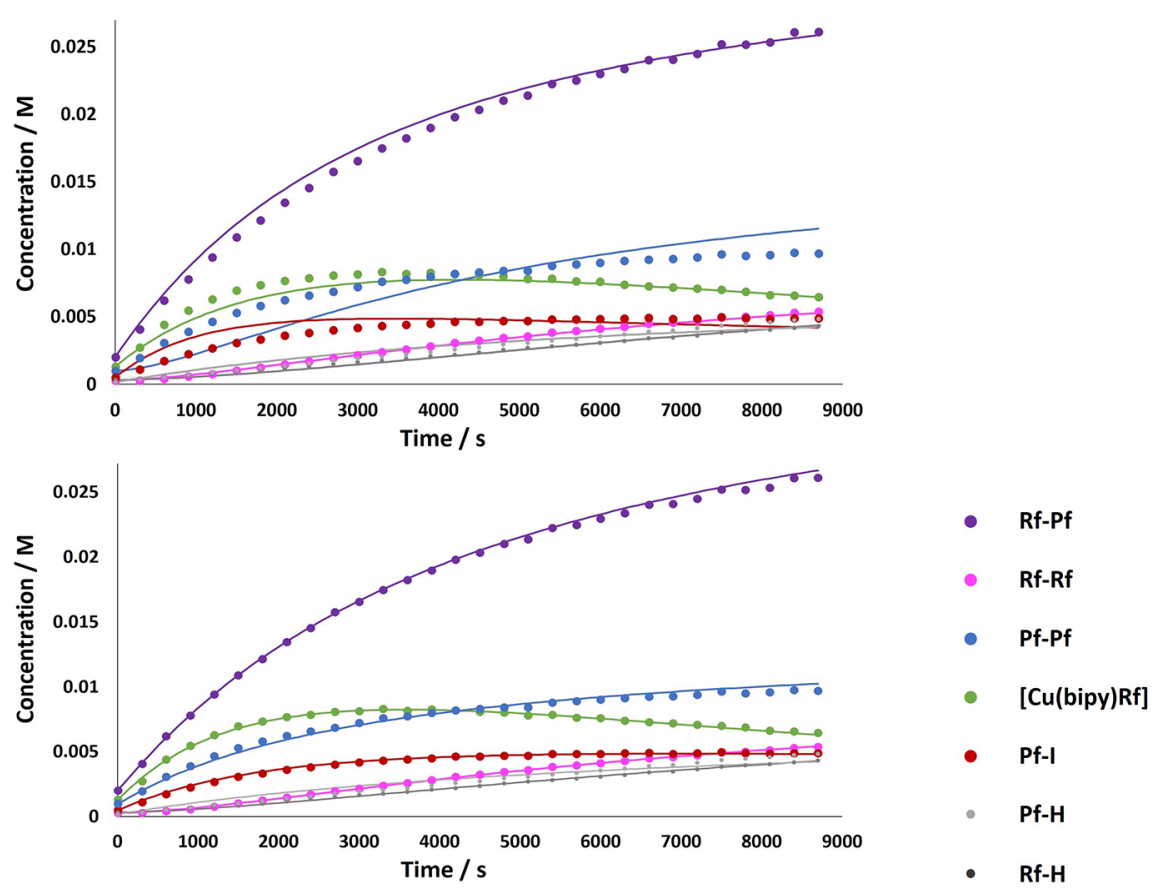

Figure 2. Experimental (dots) and best least-squares fitting (solid lines) of the products formed in the reaction of $\mathbf{1}\left(7.1 \times 10^{-2} \mathrm{M}\right)$ with $\mathrm{Rf}-\mathrm{I}(7.1$ $\times 10^{-2} \mathrm{M}$ ) in THF at $25^{\circ} \mathrm{C}$ : (purple) Rf-Pf; (pink) Rf-Rf; (blue) Pf-Pf; (green) [Cu(bipy)(Rf)]; (red) Pf-I; (dark-gray) Rf-H; (light-gray) $\mathrm{Pf}-\mathrm{H}$. The upper figure shows the fitting with model I and the lower that with model II. Note the bad fitting on the upper figure, particularly for the homocoupling products $\mathrm{Pf}-\mathrm{Pf}$ and $\mathrm{Pf}-\mathrm{I}$ (blue and red). 


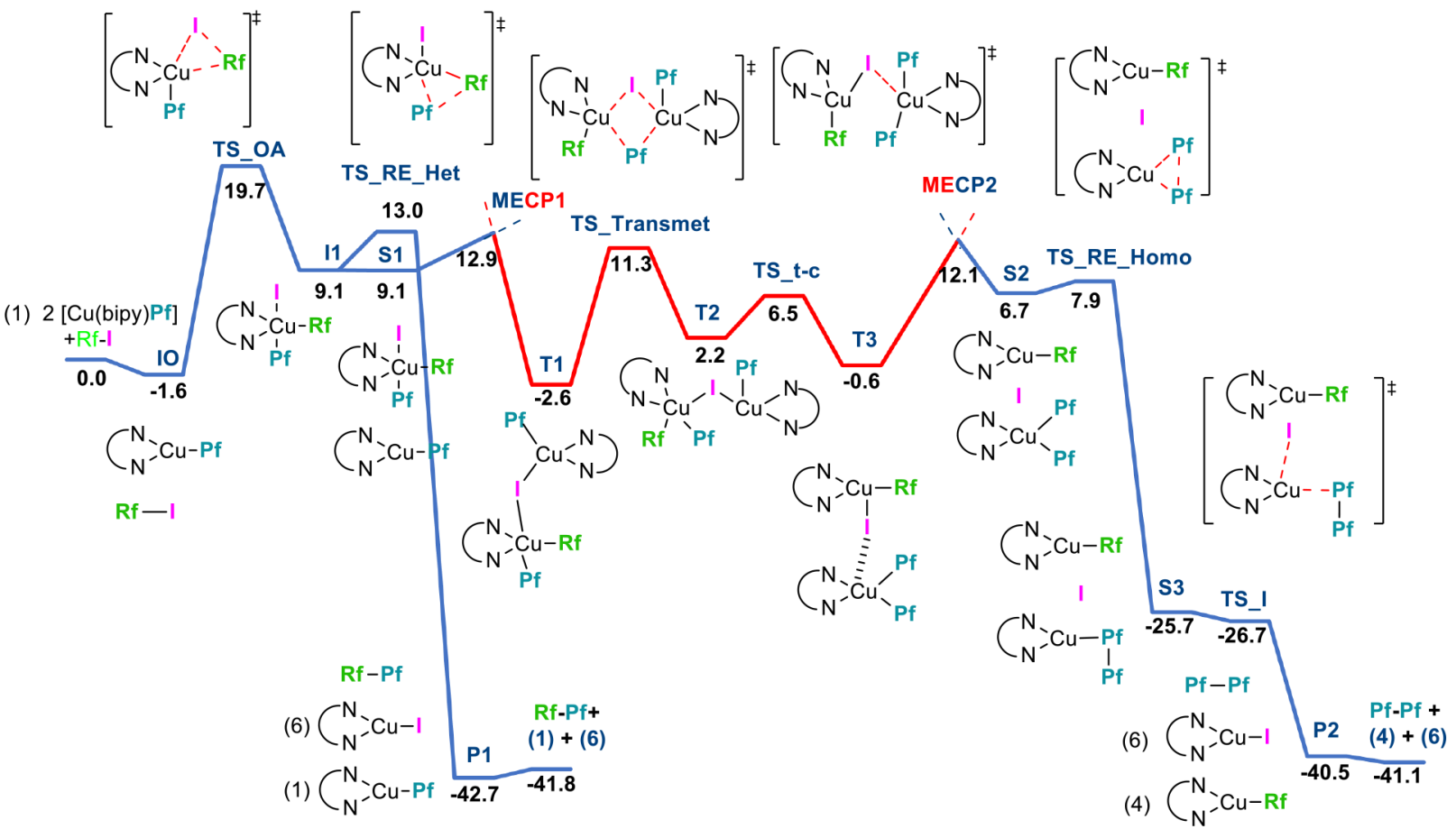

Figure 4. DFT-computed (B3LYP-D3/BS2 functional in THF) pathways for the competitive reactions of the formation of heterocoupling and homocoupling products. Relative Gibbs energies are given in $\mathrm{kcal} \mathrm{mol}^{-1}$. Blue line: singlet potential energy surface. Red line: triplet potential energy surface. S1, S2, and S3 represent intermediates in the singlet state and T1, T2, and T3 intermediates in the triplet state. Optimized structures of all of the species in the profile are displayed in the SI.

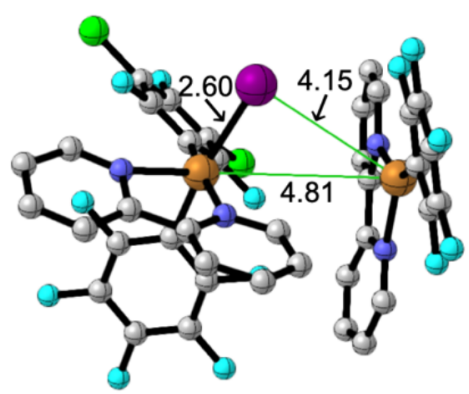

S1

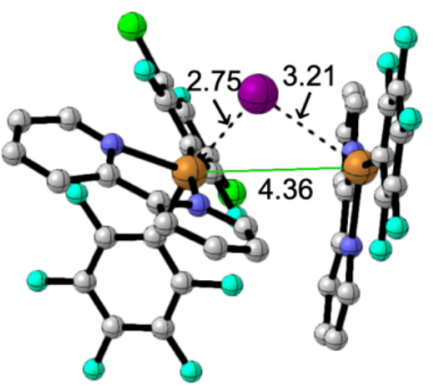

MECP1

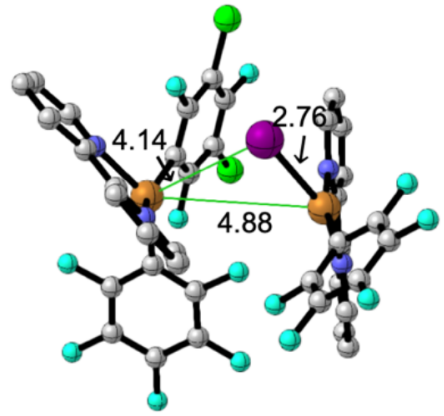

T1

Figure 5. Optimized geometries of the singlet (S1) and triplet (T1) intermediates and the corresponding minimum-energy crossing point connecting both (MECP1). Distances are in angstroms.

formation of homocoupling products, although the intimate mechanism cannot be established with the available experimental data. To disclose the mechanism of such a transformation, we have carried out DFT calculations (B3LYP-D3 functional with a SMD (solvation model based on density)/ continuum description of the tetrahydrofuran (THF) solvent (see Computational Details in the SI). The calculated Gibbs energy profile for the reaction between $\mathbf{1}$ and $\mathrm{Rf}-\mathrm{I}$ is shown in Figure 4

Heterocoupling follows the expected pathway. The oxidative addition of Rf-I to 1 takes place with an energy barrier of 21.3 $\mathrm{kcal} \mathrm{mol}^{-1}$ (TS_OA), yielding the $\mathrm{Cu}$ (III) pentacoordinate intermediate $\mathbf{I} 1{ }^{\overline{34}}$ which affords the heterocoupling product Rf-Pf after crossing a low barrier (3.9 $\mathrm{kcal} \mathrm{mol}^{-1}$; TS_RE_Het) for the reductive elimination step. An important point evidenced by the calculation is the instability of the
$\mathrm{Cu}$ (III) intermediate $\mathbf{I} 1$ that leads to a very low barrier (3.9 $\mathrm{kcal} \mathrm{mol}^{-1}$ ) for the reductive elimination step.

Because homocoupling requires the presence of a second copper center, we included in the calculation one molecule of the $\mathrm{Cu}(\mathrm{I})$ reagent 1 , present in the medium in a large excess. The presence of $\mathbf{1}$ has no effect in the stability of $\mathbf{I} \mathbf{1}$ in the singlet state ( $\mathbf{S} 1$ in Figure 4 at $9.1 \mathrm{kcal} \mathrm{mol}^{-1}$ ). However, the optimization of $\mathbf{S 1}$ (the couple I1.1) in the triplet state causes dramatic changes in the system: a much more stable intermediate T1 (at -2.6 in the Gibbs energy profile; Figure 4) is formed as a consequence of a comproportionation reaction between the $\mathrm{Cu}(\mathrm{III})$ and $\mathrm{Cu}(\mathrm{I})$ centers. The jump from the singlet $\mathrm{S} 1[\mathrm{Cu}(\mathrm{IIII})-\mathrm{Cu}(\mathrm{I})]$ to the triplet $\mathbf{T} \mathbf{1}$ [formally a $\mathrm{Cu}(\mathrm{II})-\mathrm{Cu}(\mathrm{II})$ system, see copper atomic charges in I0, S1, and T1 and the spin-density plot for T1 in the SI] takes place through a minimum-energy crossing point (MECP1) at $12.9 \mathrm{kcal} \mathrm{mol}^{-1}$. The electron transfer between 
the two copper complexes happens with the simultaneous exchange of an iodine atom. The optimized geometries of S1, MECP1, and T1 are depicted in Figure 5.

To assess the reliability of the singlet-triplet crossing, the relative energies of the singlet $\mathbf{S} 1$ and triplet $\mathbf{T} 1$ intermediates have been computed with 12 functionals containing variable percentages of Hartree-Fock exchange, using an extended basis set (BS2; see the SI). Although this energy difference is very dependent on the functional, all of the functionals agree that $\mathbf{T} 1$ is more stable than $\mathbf{S} 1$.

From T1, an easy transmetalation of Pf happens (through TS-Transmet, Figure 6), placing both Pf groups bonded to the

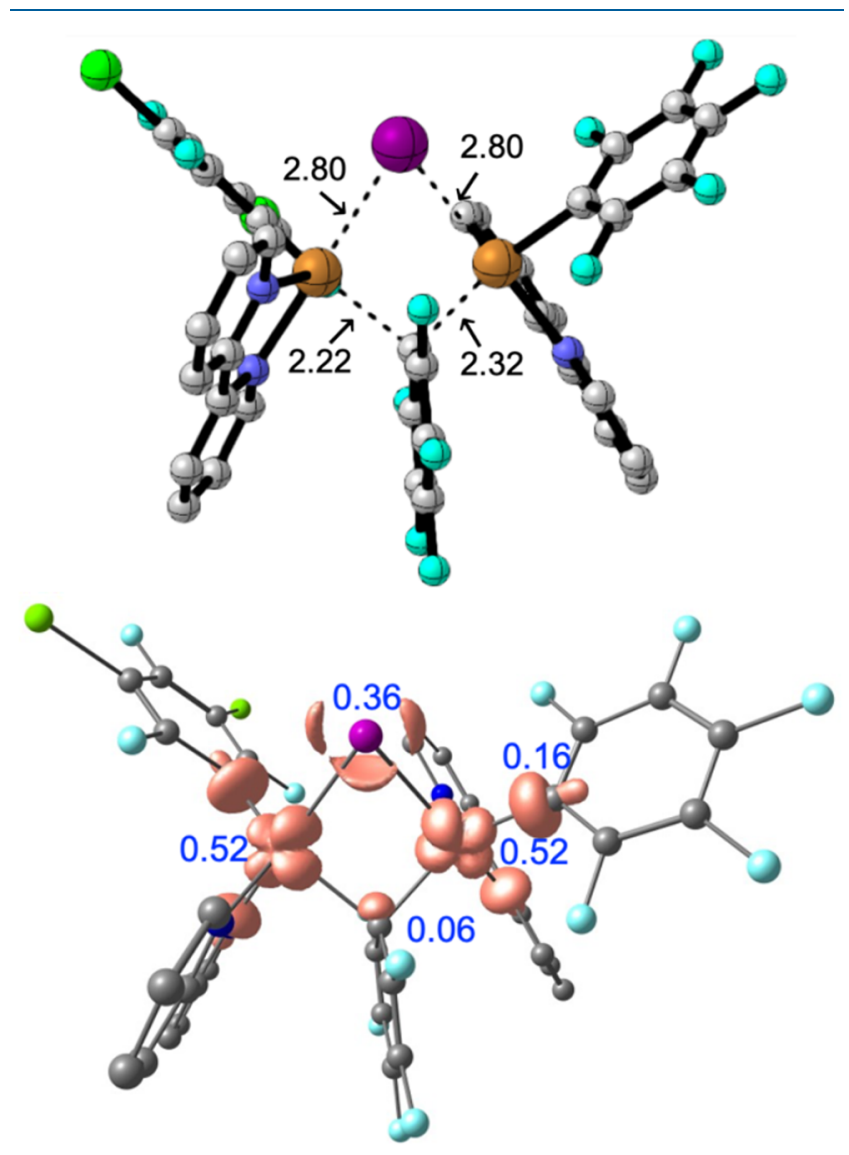

Figure 6. Optimized structure of the transmetalation transition state (TS_Transmet) (upper figure) and its spin-density plot (lower figure). In black are the distances (in angstroms), and in blue are the Mulliken spin populations.

same copper center, although mutually trans. Then, through a low barrier isomerization (TS_t-c, Figure 4), the cis-Pf intermediate is reached (T3). Recrossing from the triplet (T3) to singlet (S2) potential energy surfaces through MECP2 entails, in addition to electron transfer between the two copper centers, the detachment of an iodide. In $\mathbf{S 2}, \mathrm{Cu}(\mathrm{I})[\mathrm{Cu}($ bipy)(Rf)], $\mathrm{Cu}(\mathrm{III})$ cis- $\left[\mathrm{Cu}(\text { bipy })\left(\mathrm{Pf}_{2}\right)\right]^{+}$, and $\mathrm{I}^{-}$are present, and Pf-Pf homocoupling occurs in the $\mathrm{Cu}$ (III) center with a barrier of only $1.2 \mathrm{kcal} \mathrm{mol}^{-1}$ (TS_RE_Homo). A practically barrierless replacement of $\mathrm{Pf}-\mathrm{Pf} \bar{b} \mathrm{I}^{-}$in the coordination sphere of one copper ion (TS_I) yields the homocoupling product $(\mathrm{Pf}-\mathrm{Pf})$ and two copper(I) complexes, $[\mathrm{Cu}($ bipy $)$ (Rf)] and [Cu(bipy)I].

The computed profile depicts a situation in which the heterocoupling is a unimolecular process from the intermediate
I1, which is consistent with a kinetic reaction order of 1 on $\mathbf{1}$ for this reaction. The selectivity for the formation of homo- or heterocoupling products depends on the relative energies of MECP1 and TS_RE_Het and also on the concentration of 1, but because the selection takes place after the rate-limiting step (oxidative addition), the overall kinetic order on $\mathbf{1}$ is 1 .

Homocoupling requires the presence of a $\mathrm{Cu}(\mathrm{III})$ intermediate that can cross to the triplet potential energy surface by a comproportionation reaction with a $\mathrm{Cu}(\mathrm{I})$ center. As mentioned above, heterocoupling $\mathrm{Pf}-\mathrm{Rf}$ is the only observable reaction for nonfluorinated aryls. ${ }^{35}$ We have computed the energy profiles for a series of nonfluorinated para-substituted aryl iodides $\left(\mathrm{R}=\mathrm{H}, \mathrm{OMe}, \mathrm{Br}, \mathrm{NO}_{2}\right.$; see Figure 1). The computed Gibbs energy profiles for all of these nonfluorinated $\mathrm{Ar}-\mathrm{I}$ (see the SI) show that no metastable $\mathrm{Cu}(\mathrm{III})[\mathrm{Cu}($ bipy $) \mathrm{I}(\mathrm{Pf})(\mathrm{Ph})]$ intermediate is formed in this reaction, with the $\mathrm{Ar}-\mathrm{Pf}$ product being reached in only one step. Therefore, the comproportionation reaction with a $\mathrm{Cu}(\mathrm{I})$ intermediate cannot occur. Accordingly, transmetalation does not happen either and homocoupling products are not observed. When I-Pf or I-Rf are used, the $\mathrm{Cu}(\mathrm{III})$ intermediates benefit from the large stabilization of the $\mathrm{C}-$ $\mathrm{M}$ bonds that fluoroaryls provide, ${ }^{31}$ and intermediate $\mathbf{I 1}$ is stable enough to be captured by $\mathbf{1}$, allowing electron transfer between both copper centers to occur, yielding a biradical $\mathrm{Cu}(\mathrm{II})-\mathrm{Cu}(\mathrm{II})$ system. A fast bimolecular scrambling of aryls may take place between the $\mathrm{Cu}$ (II) centers, leading to a statistical formation of copper complexes with two Pf groups or with one Pf group and one $\mathrm{Rf}$ group. From this fast-exchange system, Pf-Pf and Pf-Rf can be formed and also $[\mathrm{Cu}($ bipy $)$ (Rf)] through the reductive elimination of Pf-I.

Finally, it is worth noting the stability of the triplets T1, T2, and $\mathrm{T} 3$ compared with the singlet $\mathrm{Cu}(\mathrm{III}) / \mathrm{Cu}(\mathrm{I})$ pairs. All of them are neutral species with bridging iodine, readily accessible from $\mathrm{Cu}(\mathrm{III})$ intermediates. These $\mathrm{Cu}(\mathrm{II})$ intermediates are kinetically labile and open new reaction pathways that cannot be predicted when only one molecule of the catalyst is considered, and they correlate with the reaction mechanisms of single copper species with binuclear complexes and with bioinorganic structures. ${ }^{36}$ In our case study, the pathway available in $\mathrm{Cu}(\mathrm{II})$ is transmetalation, which apparently is not accessible if only $\mathrm{Cu}(\mathrm{I})$ and $\mathrm{Cu}(\mathrm{III})$ species are considered.

\section{CONCLUSION}

Our study presents a case in which the abundant $\mathrm{Cu}(\mathrm{I})$ reagents intercept $\mathrm{Cu}(\mathrm{III})$ intermediates in an electron-transfer comproportionation reaction, followed by a fast transmetalation. This comproportionation reaction can also be described as an inner-sphere electron transfer coupled with a spin surface crossing. From a kinetic point of view, the participation of two copper molecules in the reaction is somewhat hidden by the fact that it takes place after the ratelimiting step, the oxidation of $\mathrm{Cu}$ (I) to $\mathrm{Cu}$ (III), although it has a clear effect on the selectivity. DFT calculations clearly show the easiness of the electron transfer and transmetalation between copper complexes. We think that this model represents well reactive systems that go through $\mathrm{Cu}(\mathrm{III})$ intermediates. In this regard, some of us have recently reported comproportionation reactions between $\mathrm{Cu}(\mathrm{III}), \mathrm{Cu}(0)$, and $\mathrm{Cu}(\mathrm{I})$ centers, yielding $\mathrm{Cu}(\mathrm{II})$ species in oxygen-bridged polynuclear copper complexes. ${ }^{37}$ In these systems, the concentration of $\mathrm{Cu}(\mathrm{I})$ species accounts for most of the overall copper, making very probable the event of its reaction 
with complexes in other oxidation states. In this case, the bimolecular comproportionation has to be taken into consideration in mechanistic proposals.

\section{ASSOCIATED CONTENT}

\section{SI Supporting Information}

The Supporting Information is available free of charge at https://pubs.acs.org/doi/10.1021/acs.inorgchem.1c01595.

Experimental section, control experiments, kinetic data, kinetic simulations and NMR spectra, crystallographic data for $\left(\mathrm{NBu}_{4}\right)\left[\mathrm{Cu}\left(\mathrm{C}_{6} \mathrm{~F}_{5}\right)_{2}\right]$, and computational methods and extended description of the computational results (PDF)

\section{Accession Codes}

CCDC 2072143 contains the supplementary crystallographic data for this paper. These data can be obtained free of charge via www.ccdc.cam.ac.uk/data_request/cif, or by emailing data_request@ccdc.cam.ac.uk, or by contacting The Cambridge Crystallographic Data Centre, 12 Union Road, Cambridge CB2 1EZ, UK; fax: +44 1223336033.

\section{AUTHOR INFORMATION}

\section{Corresponding Authors}

Agustí Lledós - Departament de Química, Edifici C.n. Universitat Autònoma de Barcelona, Cerdanyola del Valles, Catalonia 08193, Spain; 이이.org/0000-0001-7909422X; Email: agusti@klingon.uab.es

Juan A. Casares - IU CINQUIMA/Química Inorgánica, Facultad de Ciencias, Universidad de Valladolid, Valladolid 47011, Spain; orcid.org/0000-0001-8833-2066; Email: casares@qi.uva.es

\section{Authors}

Olmo Lozano-Lavilla - IU CINQUIMA/Química Inorgánica, Facultad de Ciencias, Universidad de Valladolid, Valladolid 47011, Spain; 이이.org/0000-0002-57521144

Pablo Gómez-Orellana - Departament de Química, Edifici C.n. Universitat Autònoma de Barcelona, Cerdanyola del Valles, Catalonia 08193, Spain

Complete contact information is available at: https://pubs.acs.org/10.1021/acs.inorgchem.1c01595

\section{Notes}

The authors declare no competing financial interest.

\section{ACKNOWLEDGMENTS}

The authors thank the Spanish MCIN (Projects PID2019111406GB-I00 and PID2020-116861GB-I00) and Junta de Castilla y León (Projects VA224P20 and VA062G18) for financial support.

\section{REFERENCES}

(1) (a) Nelson, T. D.; Crouch, R. D. Organic Reactions; John Wiley \& Sons, Inc., 2004; pp 265-555, Vol. 63. (b) Sperotto, E.; Van Klink, G. P. M.; Van Koten, G.; De Vries, G. J. The mechanism of the modified Ullmann reaction. Dalton Trans. 2010, 39, 10338-10351.

(2) Jones, G. O.; Liu, P.; Houk, K. N.; Buchwald, S. L. Computational Explorations of Mechanisms and Ligand-Directed Selectivities of Copper-Catalyzed Ullmann-Type Reactions. J. Am. Chem. Soc. 2010, 132, 6205-6213.
(3) Beletskaya, I. P.; Cheprakov, A. V. The Complementary Competitors: Palladium and Copper in $\mathrm{C}-\mathrm{N}$ Cross-Coupling Reactions. Organometallics 2012, 31, 7753-7808.

(4) Hirano, K.; Miura, M. Recent Advances in Copper-Mediated Direct Biaryl Coupling. Chem. Lett. 2015, 44, 868-873.

(5) (a) Thapa, S.; Shrestha, B.; Gurung, S. K.; Giri, R. CopperCatalysed Cross-Coupling: An Untapped Potential. Org. Biomol. Chem. 2015, 13, 4816-4827. (b) Cheng, L.-J.; Mankad, N. P. C-C and $\mathrm{C}-\mathrm{X}$ coupling reactions of unactivated alkyl electrophiles using copper catalysis. Chem. Soc. Rev. 2020, 49, 8036-8064.

(6) Hickman, A. J.; Sanford, M. S. High-valent organometallic copper and palladium in catalysis. Nature 2012, 484, 177-185.

(7) Casitas, A.; Ribas, X. The Role of Organometallic Copper(Iii) Complexes in Homogeneous Catalysis. Chem. Sci. 2013, 4, 23012318.

(8) Li, S.-J.; Lan, Y. Is $\mathrm{Cu}(\mathrm{III})$ a Necessary Intermediate in $\mathrm{Cu}$ Mediated Coupling Reactions? A Mechanistic Point of View. Chem. Commun. 2020, 56, 6609-6619.

(9) Zhang, S.-L.; Liu, L.; Fu, Y.; Guo, Q.-X. Theoretical Study on Copper(I)-Catalyzed Cross-Coupling between Aryl Halides and Amides. Organometallics 2007, 26, 4546-4554.

(10) Giri, R.; Brusoe, A.; Troshin, K.; Wang, J. Y.; Font, M.; Hartwig, J. F. Mechanism of the Ullmann Biaryl Ether Synthesis Catalyzed by Complexes of Anionic Ligands: Evidence for the Reaction of Iodoarenes with Ligated Anionic CuI Intermediates. J. Am. Chem. Soc. 2018, 140, 793-806.

(11) Yu, H.-Z.; Jiang, Y.-Y.; Fu, Y.; Liu, L. Alternative Mechanistic Explanation for Ligand-Dependent Selectivities in Copper-Catalyzed N- and O-Arylation Reactions. J. Am. Chem. Soc. 2010, 132, 1807818091.

(12) Kalkman, E. D.; Mormino, M. G.; Hartwig, J. F. Unusual Electronic Effects of Ancillary Ligands on the Perfluoroalkylation of Aryl Iodides and Bromides Mediated by Copper(I) Pentafluoroethyl Complexes of Substituted Bipyridines. J. Am. Chem. Soc. 2019, 141, 19458-19465.

(13) Tye, J. W.; Weng, Z.; Johns, A. M.; Incarvito, C. D.; Hartwig, J. F. Copper Complexes of Anionic Nitrogen Ligands in the Amidation and Imidation of Aryl Halides. J. Am. Chem. Soc. 2008, 130, 99719983.

(14) Tye, J. W.; Weng, Z.; Giri, R.; Hartwig, J. F. Copper(I) Phenoxide Complexes in the Etherification of Aryl Halides. Angew. Chem., Int. Ed. 2010, 49, 2185-2189.

(15) Huang, Z.; Hartwig, J. F. Copper(I) Enolate Complexes in $\alpha$ Arylation Reactions: Synthesis, Reactivity, and Mechanism. Angew. Chem., Int. Ed. 2012, 51, 1028-1032.

(16) Konovalov, A. I.; Lishchynskyi, A.; Grushin, V. V. Mechanism of Trifluoromethylation of Aryl Halides with $\mathrm{CuCF}_{3}$ and the Ortho Effect. J. Am. Chem. Soc. 2014, 136, 13410-13425.

(17) Lin, X.; Hou, C.; Li, H.; Weng, Z. Decarboxylative Trifluoromethylating Reagent $\left[\mathrm{Cu}\left(\mathrm{O}_{2} \mathrm{CCF}_{3}\right)\right.$ (Phen)] and Difluorocarbene Precursor $\left[\mathrm{Cu}(\mathrm{Phen})_{2}\right]\left[\mathrm{O}_{2} \mathrm{CCF}_{2} \mathrm{Cl}\right]$. Chem. - Eur. J. 2016, 22, 2075-2084.

(18) Lu, Z.; Liu, H.; Liu, S.; Leng, X.; Lan, Y.; Shen, Q. A Key Intermediate in Copper-Mediated Arene Trifluoromethylation, $\left[\mathrm{NBu}_{4} \mathrm{~N}\right]\left[\mathrm{Cu}(\mathrm{Ar})\left(\mathrm{CF}_{3}\right)_{3}\right]$ : Synthesis, Characterization, and $\mathrm{C}\left(\mathrm{sp}^{2}\right)-$ $\mathrm{CF}_{3}$ Reductive Elimination. Angew. Chem., Int. Ed. 2019, 58, 85108514.

(19) Paeth, M.; Tyndall, S. B.; Chen, L. Y.; Hong, J. C.; Carson, W. P.; Liu, X.; Sun, X.; Liu, J.; Yang, K.; Hale, E. M.; Tierney, D. L.; Liu, B.; Cao, Z.; Cheng, M.-J.; Goddard, W. A., III; Liu, W. Csp ${ }^{3}-$ Csp $^{3}$ Bond-Forming Reductive Elimination from Well-Defined Copper(III) Complexes. J. Am. Chem. Soc. 2019, 141, 3153-3159.

(20) Note that assignation of the oxidation states is also an object of debate. For instance, see: (a) Hoffmann, R.; Alvarez, S.; Mealli, C.; Falceto, A.; Cahill, T. J.; Zeng, T.; Manca, G. From Widely Accepted Concepts in Coordination Chemistry to Inverted Ligand Fields. Chem. Rev. 2016, 116, 8173-8192. (b) DiMucci, I. M.; Lukens, J. T.; Chatterjee, S.; Carsch, K. M.; Titus, C. J.; Lee, S. J.; Nordlund, D.; 
Betley, T. A.; MacMillan, S. N.; Lancaster, K. M. The Myth of $\mathrm{d}^{8}$ Copper(III). J. Am. Chem. Soc. 2019, 141, 18508-18520.

(21) Akatyev, N.; Il'in, M.; Il'in, M., Jr.; Peregudova, S.; Peregudov, A.; Buyanovskaya, A.; Kudryavtsev, K.; Dubovik, A.; Grinberg, V.; Orlov, V.; Pavlov, A.; Novikov, V.; Volkov, I.; Belokon, Y. ChanEvans-Lam C-N Coupling Promoted by a Dinuclear Positively Charged $\mathrm{Cu}$ (II) Complex. Catalytic Performance and Some Evidence for the Mechanism of CEL Reaction Obviating $\mathrm{Cu}(\mathrm{III}) / \mathrm{Cu}(\mathrm{I})$ Catalytic Cycle. ChemCatChem 2020, 12, 3010-3021.

(22) delPozo, J.; Casares, J. A.; Espinet, P. In Situ Generation of $\mathrm{ArCu}$ from $\mathrm{CuF}_{2}$ Makes Coupling of Bulky Aryl Silanes Feasible and Highly Efficient. Chem. - Eur. J. 2016, 22, 4274-4284.

(23) Kim, U. B.; Jung, D. J.; Jeon, H. J.; Rathwell, K.; Lee, S. Synergistic Dual Transition Metal Catalysis. Chem. Rev. 2020, 120, 13382-13433.

(24) (a) Pérez-Temprano, M. H.; Casares, J. A.; Espinet, P. Bimetallic catalysis using transition and group 11 metals: An emerging tool for C-C coupling and other reactions. Chem. - Eur. J. 2012, 18, 1864-1884. (b) Pye, D. R.; Mankad, N. P. Bimetallic catalysis for C$\mathrm{C}$ and $\mathrm{C}-\mathrm{X}$ coupling reactions. Chem. Sci. 2017, 8, 1705-1718.

(25) The DFT-computed Gibbs energy barrier (298.15 K) is 24.1 $\mathrm{kcal} \mathrm{mol}{ }^{-1}$, in very good agreement with the experimental value.

(26) Yoshikai, N.; Nakamura, E. Mechanisms of Nucleophilic Organocopper(I) Reactions. Chem. Rev. 2012, 112, 2339-2372.

(27) (a) Leoni, P.; Pesquali, M.; Ghilardi, C. A. Isolation and Crystal and Molecular Structure of a Rare Example of a Mononuclear Organo-Cuprate. J. Chem. Soc., Chem. Commun. 1983, 6, 240-241. (b) Dubinina, G. G.; Furutachi, H.; Vicic, D. A. Active Trifluoromethylating Agents from Well-Defined Copper(I) $-\mathrm{CF}_{3}$ Complexes. J. Am. Chem. Soc. 2008, 130, 8600-8601. (c) Strieter, E. R.; Blackmond, D. G.; Buchwald, S. L. The Role of Chelating Diamine Ligands in the Goldberg Reaction: A Kinetic Study on the Copper-Catalyzed Amidation of Aryl Iodides. J. Am. Chem. Soc. 2005, 127, 4120-4121.

(28) The equilibria show higher $K_{\text {eq }}$ values when measured in more polar solvents. See also refs 13 and 14.

(29) (a) Giri, R.; Hartwig, J. F. Cu(I)-Amido Complexes in the Ullmann Reaction: Reactions of $\mathrm{Cu}(\mathrm{I})$-Amido Complexes with Iodoarenes with and without Autocatalysis by CuI. J. Am. Chem. Soc. 2010, 132, 15860-15863. (b) Tye, J. W.; Weng, Z.; Giri, R.; Hartwig, J. F. Copper(I) Phenoxide Complexes in the Etherification of Aryl Halides. Angew. Chem., Int. Ed. 2010, 49, 2185-2189. (c) Strieter, E. R.; Blackmond, D. G.; Buchwald, S. L. The role of chelating diamine ligands in the Goldberg reaction: A kinetic study on the coppercatalyzed amidation of aryl iodides. J. Am. Chem. Soc. 2005, 127, 4120-4121. (d) Dubinina, G. G.; Ogikubo, J.; Vicic, D. A. Structure of Bis(Trifluoromethyl)Cuprate and Its Role in Trifluoromethylation Reactions. Organometallics 2008, 27, 6233-6235.

(30) This agrees with most of the proposals for oxidative addition reactions on trigonal $\mathrm{Cu}(\mathrm{I})$ intermediates. See, for instance, refs 5,10 , and 12 .

(31) Clot, E.; Mégret, C.; Eisenstein, O.; Perutz, R. N. Exceptional Sensitivity of Metal-Aryl Bond Energies to Ortho-Fluorine Substituents: Influence of the Metal, the Coordination Sphere, and the Spectator Ligands on $\mathrm{M}-\mathrm{C} / \mathrm{H}-\mathrm{C}$ Bond Energy Correlations. J. Am. Chem. Soc. 2009, 131, 7817-7827.

(32) Other possible pathways, such the formation of intermediates of the type $\left[\mathrm{Cu}(\mathrm{bipy})(\mathrm{Pf})(\mathrm{Rf})_{2}\right]$, have been considered and are discussed in the SI.

(33) We have shown that $\mathrm{C}_{6} \mathrm{~F}_{5}$ and $\mathrm{C}_{6} \mathrm{Cl}_{2} \mathrm{~F}_{3}$ behave as electronically equivalent groups. For instance, see: Pérez-Iglesias, M.; LozanoLavilla, O.; Casares, J. A. $\left[\mathrm{Cu}\left(\mathrm{C}_{6} \mathrm{Cl}_{2} \mathrm{~F}_{3}\right)(\mathrm{tht})\right]_{4}$ : An Extremely Efficient Catalyst for the Aryl Scrambling between Palladium Complexes. Organometallics 2019, 38, 739-742. and references cited therein.

(34) This value fits nicely with the experimental value $\Delta G^{\ddagger}=20.8$ $\mathrm{kcal} \mathrm{mol}^{-1}$ obtained from the kinetic data.

(35) Very small amounts of Pf $-\mathrm{H}$ and Pf-Pf are always formed when complex $\mathbf{1}$ is in solution for some hours due to adventitious amounts of water and oxygen in solution. See the SI.
(36) Desnoyer, A. N.; Nicolay, A.; Rios, P.; Ziegler, M. S.; Tilley, T. D. Bimetallics in a Nutshell: Complexes Supported by Chelating Naphthyridine-Based Ligands. Acc. Chem. Res. 2020, 53, 1944-1956.

(37) Álvarez, M.; Molina, F.; Fructos, M. R.; Urbano, J.; Álvarez, E.; Sodupe, M.; Lledós, A.; Pérez, P. J. Aerobic Intramolecular CarbonHydrogen Bond Oxidation Promoted by $\mathrm{Cu}(\mathrm{I})$ Complexes. Dalton Trans. 2020, 49, 14647-14655. 